\title{
Electrocardiographic Abnormalities in Heart Failure Patients at a Teaching Hospital in Kumasi, Ghana \\ Isaac Kofi Owusu ${ }^{1,2 *}$, Yaw Adu-Boakye ${ }^{2}$ and Lambert Tetteh Appiah ${ }^{2}$
}

${ }^{1}$ Department of Medicine, School of Medical Sciences, College of Health Sciences, Kwame Nkrumah University of Science and Technology, Kumasi, Ghana ${ }^{2}$ Department of Medicine, Komfo Anokye Teaching Hospital, Kumasi, Ghana

\begin{abstract}
The resting 12-lead Electrocardiogram (ECG) is very useful in the diagnosis, prognosis and treatment of heart failure. There are limited data on the prevalence of ECG abnormalities in heart failure in Ghana. This retrospective study was therefore designed to determine the prevalence of ECG abnormalities among heart failure patients attending a cardiac clinic at the Komfo Anokye Teaching Hospital (KATH), Kumasi, Ghana. Medical records of 398 patients diagnosed with heart failure were selected from the cardiac clinic, using simple random sampling. The demographic, clinical and chest X-ray characteristics of the patients were examined. The 12-lead resting ECGs were obtained from 394 of the patients. The ECGs were abnormal in $93 \%(n=367)$ of the patients. The main ECG abnormalities included: left ventricular hypertrophy $(43.7 \%)$, left axis deviation (39.6\%), left bundle branch block $(19.2 \%)$, and left atrial enlargement $(25.6 \%)$. Arrhythmias seen included: ventricular extrasystoles $(11.2 \%)$, atrial fibrillation $(8.9 \%)$, complete heart block (5.3\%), and ventricular tachycardia (3.6\%).
\end{abstract}

In conclusion, our study has shown that ECG abnormalities are very common among heart failure patients attending cardiac clinic in Kumasi, Ghana.

Keywords: Arrhythmia; Atrial fibrillation; Non-sustained ventricular tachycardia; Atrial flutter; Heart failure

\section{Introduction}

The resting 12-lead Electrocardiogram (ECG) is widely available in the developed world. The ECG is a non-invasive and relatively easy bedside test to perform. It is mostly used cardiovascular diagnostic test, and it is performed by cardiologists and other physicians who are not cardiologists. However, the ECG is largely unavailable in many healthcare facilities in sub-Saharan African.

The ECG is an essential test in the evaluation of patients with heart failure. The European Society of Cardiology and the National Institute for Clinical Excellence of UK recommend the use of the ECG in the diagnosis of patients with suspected heart failure $[1,2]$.

The ECG is very useful in the diagnosis and prognosis of heart failure. It also provides important information for decisions about treatment of heart failure. The ECG may identify the aetiology of the heart failure. It may also determine the precipitating factor of the heart failure in patients presenting with acute heart failure.

The ECG shows the heart rate and the rhythm, electrical conduction and chamber enlargement. Studies have shown that heart failure is very unlikely (likelihood $<2 \%$ ) if patients present acutely and the ECG is completely normal [3-9]. In patients with a non-acute presentation, a normal ECG has a somewhat lower negative predictive value (likelihood, 10-14\%) [4-6,9].

There are limited data on the prevalence of ECG abnormalities in heart failure in Ghana. This study was therefore designed to determine the prevalence of ECG abnormalities among heart failure patients attending a cardiac clinic at the KATH, Kumasi, Ghana.

\section{Materials and Methods}

This was a retrospective study carried out at the cardiac clinic of Komfo Anokye Teaching Hospital (KATH), Kumasi, Ghana. Ethical approval was obtained from the appropriate ethical committee. Medical records of 398 patients diagnosed with heart failure were selected from the cardiac clinic, using simple random sampling. The demographic, clinical, chest X-ray and 12-lead resting Electrocardiographic (ECG) characteristics of the patients were examined. Heart failure was diagnosed, using the modified Framingham criteria for the diagnosis of heart failure [10-12].

\section{Major criteria included}

Paroxysmal nocturnal dyspnoea, raised jugular venous pressure, clinical cardiomegaly, basal crepitations, S3 gallop, clinical acute pulmonary oedema, pulmonary upper lobe blood diversion on chest $\mathrm{X}$-ray (or pulmonary oedema on chest X-ray).

\section{Minor criteria included}

Tachycardia, orthopnoea, exertional dyspnoea, nocturnal cough, hepatomegaly, pleural effusion, diuretic use.

Heart failure was diagnosed if the patient had two major and one minor or one major and two minor criteria. Resting 12-lead ECGs were obtained from 394 of the heart failure patients. The ECGs were examined for the heart rate, the rhythm, electrical conduction, chamber enlargement, arrhythmias, and other abnormalities. Left ventricular hypertrophy was diagnosed using Scott's criteria (Table 1) [13].

*Corresponding author: Isaac Kofi Owusu, Department of Medicine School of Medical Sciences, College of Health Sciences, Kwame Nkrumah University of Science and Technology, Kumasi and Department of Medicine, Komfo Anokye Teaching Hospital, Kumasi, Ghana, Tel: +233 244565702 ; E-mail: ikeowusu@yahoo.com

Received January 06, 2014; Accepted February 06, 2014; Published February 13,2014

Citation: Owusu IK, Boakye YA, Appiah LT (2014) Electrocardiographic Abnormalities in Heart Failure Patients at a Teaching Hospital in Kumasi, Ghana. J Cardiovasc Dis Diagn 2: 142. doi:10.4172/2329-9517.1000142

Copyright: $\odot 2014$ Owusu IK, et al. This is an open-access article distributed under the terms of the Creative Commons Attribution License, which permits unrestricted use, distribution, and reproduction in any medium, provided the original author and source are credited. 
Citation: Owusu IK, Boakye YA, Appiah LT (2014) Electrocardiographic Abnormalities in Heart Failure Patients at a Teaching Hospital in Kumasi, Ghana. J Cardiovasc Dis Diagn 2: 142. doi:10.4172/2329-9517.1000142

Page 2 of 3

\begin{tabular}{|c|c|c|}
\hline Limb leads & $\mathrm{R}$ in $1+\mathrm{S}$ in 3 & More than $25 \mathrm{~mm}$ \\
\hline & $\mathrm{R}$ in a $\mathrm{VL}$ & More than $7.5 \mathrm{~mm}$ \\
\hline Chest leads & $\mathrm{S}$ in $\mathrm{V}_{1}$ or $\mathrm{V}_{2}+\mathrm{R}$ in $\mathrm{V}_{5}$ or $\mathrm{V}_{6}$ & More than $35 \mathrm{~mm}$ \\
\hline & $\mathrm{R}$ in $\mathrm{V}_{5}$ or $\mathrm{V}_{6}$ & More than $26 \mathrm{~mm}$ \\
\hline & $\mathrm{R}+\mathrm{S}$ in any $\mathrm{V}$ lead & More than $45 \mathrm{~mm}$ \\
\hline
\end{tabular}

Table 1: Left ventricular hypertrophyusing Scott's criteria

\section{Statistical analysis}

Data from the patients' medical records were entered into a Microsoft Excel (2010) sheet. Data were cleaned and abnormal variable and wrong entry removed or changed. Data were then exported into SPSS 12.0 software for analysis. Descriptive analysis of baseline parameters was provided. Measure of central tendency using mean was calculated, and measure of spread using standard deviation and range were also calculated.

\section{Results}

Three hundred and ninety-eight (398) heart failure patients were studied. The demographic characteristics of the patients have been published elsewhere [14]. ECGs were obtained from 394 patients. The ECGs were abnormal in $93 \%(n=367)$ of the patients, and normal in $7 \%(n=27)$ of the patients. Figure 1 shows the heart rate of the heart failure patients. The heart rate of the patients ranged from 28-197 beats/minute with the mean ( \pm standard deviation) heart rate of $84.9( \pm$ 25 ) beats/minute. The QRS duration ranged from 60-194 milliseconds with the mean ( \pm standard deviation) QRS duration of 98.7 ( 27.6) milliseconds.

Tables 2 and 3 shows the prevalence of arrhythmia and other ECG abnormalities seen in the heart failure patients. The main ECG abnormalities included: left ventricular hypertrophy (43.7\%), left axis deviation (39.6\%), left bundle branch block (19.2\%), and left atrial enlargement (25.60\%). Arrhythmias seen included: ventricular extrasystoles (11.2\%), atrial fibrillation (8.9\%), complete heart block (5.3), and ventricular tachycardia (3.6\%).

\section{Discussion}

Our study found out that $93 \%$ ( $n=367$ ) of the ECGs examined were abnormal, and only $7 \%(\mathrm{n}=27)$ of the ECGs were normal. This finding is similar to what was reported by Khan et al. who found only 136 $(<2 \%)$ normal ECGs out of 9315 ECGs of heart failure patients [9]. This study has clearly shown that ECG abnormalities are highly prevalent among patients with heart failure in Kumasi, Ghana. Other studies have also shown that ECG abnormalities are not only common in heart failure patients, but also in patients with higher risks for cardiovascular disease $[3-7,9,15,16]$.

ECG left ventricular hypertrophy has been recognized as a risk factor for cardiovascular disease and cardiac death for some time [17-19]. Studies have shown higher prevalence in blacks than the caucasian race [20-22]. The reason for the higher prevalence rate of left ventricular hypertrophy among black populations is not clear. In this study, the most common ECG abnormality was LVH which was seen in $43.7 \%$ of the heart failure patients. Earlier study among hypertensive heart failure patients in Kumasi, Ghana found a higher prevalence of left ventricular hypertrophy (91.5\%) [15]. Uncontrolled hypertension leads to left ventricular pressure overload which eventually results in left ventricular concentric hypertrophy. Left ventricular hypertrophy therefore, tends to be present in almost all hypertensive patients who present with heart failure.
The prevalence of atrial fibrillation in our study was $8.9 \%$. Higher prevalence rates have been reported by earlier studies $[9,22,23]$. A study in Kano, Nigeria found a prevalence rate of atrial fibrillation among heart failure patients as 19\% [23]. Another study in South-West Nigeria reported a prevalence rate of $20.7 \%$ [24]. Khan et al. found a higher prevalence rate $(27 \%)$ of atrial fibrillation and atrial flutter among heart failure patients in a multi-centre study [9]. Identification of atrial fibrillation in heart failure is very important because current guidelines recommend that these patients should receive anticoagulants, unless contraindicated [1].

The prevalence rate of left bundle branch block in our study was $19.3 \%$; this is higher than the prevalence rate reported in Kano, Nigeria [23]. Studies have shown that left bundle branch block is associated with an increased risk of cardiovascular mortality [23,25-27]. The ECG has an important role in guiding therapy. Besides patients with atrial fibrillation who might require anticoagulant treatment, several treatment modalities are now available for patients with heart failure depending on certain ECG abnormalities present [1,28,29]. For

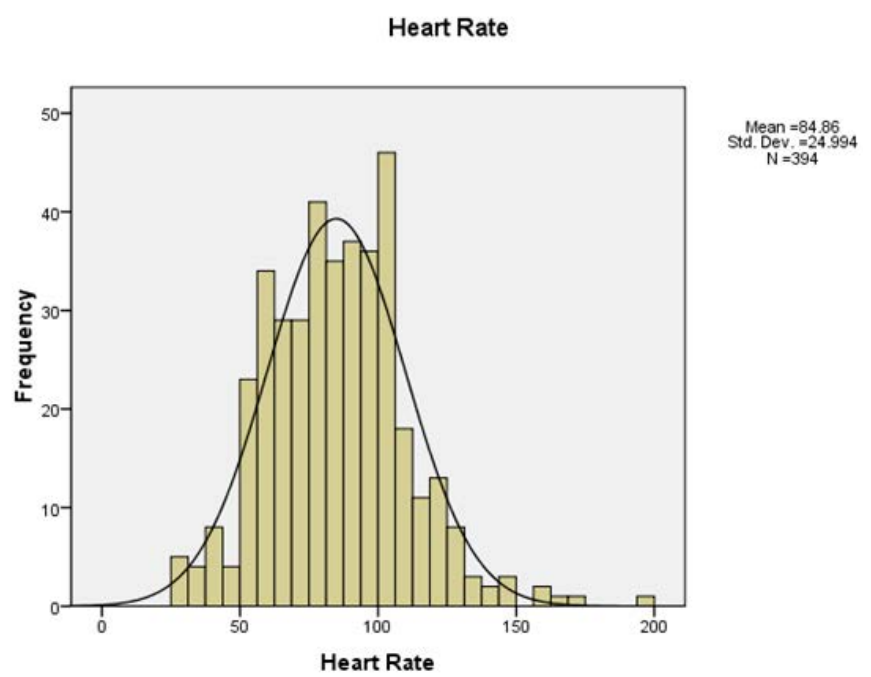

Figure 1: Histogram showing the heart rate of the heart failure patients.

\section{Arrhythmia N \% Heart Rate (Beats/Minute)Mean Range}

Sinus Rhythm Disorder

Sinus Tachycardia8120.5113101-139

Sinus Bradycardia369.15338-59

Supraventricular Arrhythmias

Atrial Fibrillation358.99552-168

Atrial Flutter51.310075-150

Junctional Tachycardia61.5163150-180

Supraventricular Extrasystoles133.39055-118

Ventricular Arrhythmias

Ventricular Tachycardia143.6160150-197

Ventricular Extrasystoles 4411.291 46-151

Conduction Defects

Complete Heart Block215.33122-40

Second Degree Atrioventricular Block92.35042-60

Complete Left Bundle Branch Block7619.3

Left Anterior Hemiblock348.6

Left Posterior Hemiblock41

Complete Right Bundle Branch Block379.4

Table 2: The prevalence of arrhythmia among the heart failure patients. 
Citation: Owusu IK, Boakye YA, Appiah LT (2014) Electrocardiographic Abnormalities in Heart Failure Patients at a Teaching Hospital in Kumasi, Ghana. J Cardiovasc Dis Diagn 2: 142. doi:10.4172/2329-9517.1000142

\begin{tabular}{|c|c|}
\hline ECG Abnormality & Percent \\
\hline Left ventricular hypertrophy & 43.70 \\
\hline Right ventricular hypertrophy & 6.70 \\
\hline Left atrial enlargement & 25.60 \\
\hline Right atrial enlargement & 10.50 \\
\hline Biatrial enlargement & 6.70 \\
\hline Left axis deviation & 39.60 \\
\hline Right axis deviation & 7 \\
\hline
\end{tabular}

Table 3: Other ECG abnormalities seen in the patients.

instance, QRS duration of $\geq 120 \mathrm{~ms}$ in a patient with heart failure indicates the need for evaluation for device therapy, including implantable defibrillators and cardiac resynchronization therapy [29]. The ECG provides an accurate and objective measure of heart rate that may be used to guide both pharmacological and device therapy.

\section{Conclusion}

In conclusion, our study has shown that ECG abnormalities are very common among heart failure patients attending cardiac clinic in Kumasi, Ghana. The ECG is very useful not only in the diagnosis and aetiology of heart failure but also it helps in identifying important complications of heart failure that might influence the choice of treatment.

\section{Acknowledgement}

The authors would like to express their sincere gratitude to the staff at the cardiac clinic of the Komfo Anokye Teaching Hospital, Kumasi, Ghana for their support. Without their co-operation this study would not have been done.

\section{References}

1. McMurray JJ, Adamopoulos S, Anker SD, Auricchio A, Böhm M, et al. (2012) ESC Guidelines for the diagnosis and treatment of acute and chronic heart failure 2012: The Task Force for the Diagnosis and Treatment of Acute and Chronic Heart Failure 2012 of the European Society of Cardiology. Developed in collaboration with the Heart Failure Association (HFA) of the ESC. Eur Heart J 33: 1787-1847.

2. The National Institute for Clinical Excellence (2003) Management of chronic heart failure in adults in primary and secondary care. Nice Guideline 5.

3. Davie AP, Francis CM, Caruana L, Sutherland GR, McMurray JJ (1997) Assessing diagnosis in heart failure: which features are any use? QJM 90: 335-339.

4. Mant J, Doust J, Roalfe A, Barton P, Cowie MR, et al. (2009) Systematic review and individual patient data meta-analysis of diagnosis of heart failure, with modelling of implications of different diagnostic strategies in primary care. Health Technol Assess 13: 1-207, iii.

5. Davie AP, Francis CM, Love MP, Caruana L, Starkey IR, et al. (1996) Value of the electrocardiogram in identifying heart failure due to left ventricular systolic dysfunction. BMJ 312: 222.

6. Thomas JT, Kelly RF, Thomas SJ, Stamos TD, Albasha K, et al. (2002) Utility of history, physical examination, electrocardiogram, and chest radiograph for differentiating normal from decreased systolic function in patients with heart failure. Am J Med 112: 437-445

7. Khunti K, Squire I, Abrams KR, Sutton AJ (2004) Accuracy of a 12-lead electrocardiogram in screening patients with suspected heart failure for open access echocardiography: a systematic review and meta-analysis. Eur J Heart Fail 6: 571-576.

8. Madias JE (2011) Why recording of an electrocardiogram should be required in every inpatient and outpatient encounter of patients with heart failure. Pacing Clin Electrophysiol 34: 963-967.
9. Khan NK, Goode KM, Cleland JG, Rigby AS, Freemantle N, et al. (2007) Prevalence of ECG abnormalities in an international survey of patients with suspected or confirmed heart failure at death or discharge. Eur J Heart Fail 9: 491-501.

10. Owusu IK (2007) Causes of heart failure as seen in Kumasi, Ghana. The Int J Third World Med 5.

11. Amoah AG, Kallen C (2000) Aetiology of heart failure as seen from a National Cardiac Referral Centre in Africa. Cardiology 93: 11-18.

12. McKee PA, Castelli WP, McNamara PM, Kannel WB (1971) The natural history of congestive heart failure: the Framingham study. N Engl J Med 285: 14411446.

13. Scott RC (1960) The electrocardiographic diagnosis of left ventricular hypertrophy. Am Heart J 59: 154-155.

14. Owusu IK, Boakye YA (2013) Prevalence and aetiology of heart failure in patient seen at a Teaching Hospital in Ghana. J Cardiovasc Dis Diagn 1: 131.

15. Owusu IK (2007) Electrocardiographic Left Ventricular Hypertrophy in Patients Seen With Hypertensive Heart Failure. The Internet Journal of Third World Medicine 6.

16. Dzudie A, Choukem SP, Adam AK, Kengne AP, Gouking P, et al. (2012) Prevalence and determinants of electrocardiographic abnormalities in subSaharan African individuals with type 2 diabetes. Cardiovasc J Afr 23: 533-537.

17. Tsutsui H, Tsuchihashi M, Takeshita A (2001) Mortality and readmission of hospitalized patients with congestive heart failure and preserved versus depressed systolic function. Am J Cardiol 88: 530-533.

18. Varela-Roman A, Gonzalez-Juanatey JR, Basante P (2002) Clinica characteristics and prognosis of hospitalised in patients with heart failure and preserved or reduced left ventricular ejection fraction. Heart 88: 249-254.

19. Ho KK, Pinsky JL, Kannel WB, Levy D (1993) The epidemiology of heart failure: the Framingham Study. J Am Coll Cardiol 22: 6A-13A.

20. Kizer JR, Arnett DK, Bella JN (2004) Differences in left ventricular structure between black and white hypertensive adults: the Hypertension Genetic Epidemiology Network study. Hypertension 43:1182-1188.

21. Ike SO, Onwubere BJ (2003) The relationship between diastolic dysfunction and level of blood pressure in Blacks. Ethn Dis 13: 463-469.

22. Isezuo AS, Omotoso AB, Araoye MA, Carr J, Corrah T (2003) Determinants of prognosis among black Africans with hypertensive heart failure. Afr J Med Med Sci 32: 143-149.

23. Karaye KM, Sani MU (2008) Factors associated with poor prognosis among patients admitted with heart failure in a Nigerian tertiary medical centre: a cross-sectional study. BMC Cardiovas Disord 8: 16.

24. Familoni OB, Olunuga TO, Olufemi BW (2007) A clinical study of pattern and factors affecting outcome in Nigerian patients with advanced heart failure. Cardiovasc J Afr 18: 308-311.

25. Mathewson FA, Manfreda J, Tate RB, Cuddy TE (1987) The University of Manitoba Follow-up Study--an investigation of cardiovascular disease with 35 years of follow-up (1948-1983). Can J Cardiol 3: 378-382.

26. Ostör E, Schnohr P, Jensen G, Nyboe J, Hansen AT (1981) Electrocardiographic findings and their association with mortality in the Copenhagen City Heart Study. Eur Heart J 2: 317-328.

27. Whincup PH, Wannamethee G, Macfarlane PW, Walker M, Shaper AG (1995) Resting electrocardiogram and risk of coronary heart disease in middle-aged British men. J Cardiovasc Risk 2: 533-543.

28. Hawkins NM, Wang D, McMurray JJ, Pfeffer MA, Swedberg K, et al. (2007) Prevalence and prognostic impact of bundle branch block in patients with heart failure: evidence from the CHARM programme. Eur J Heart Fail 9: 510-517.

29. Cleland JG, Daubert JC, Erdmann E, Freemantle N, Gras D, et al. (2005) The effect of cardiac resynchronization on morbidity and mortality in heart failure. $N$ Engl J Med 352: 1539-1549. 